\title{
Eugen Hadamovsky e a teoria da propaganda totalitária na Alemanha nazista
}

\author{
Francisco Rüdiger
}

Resumo: A propaganda nazista marcou era na história da comunicação política, mas não foi padrão o enquadramento conceitual que lhe deram seus próprios teóricos. O artigo estabelece essa premissa para analisar a corrente de entendimento representada por Eugen Hadamovsky. A primeira seção prepara a tarefa, procedendo a uma caracterização histórica da chamada propaganda totalitária. O bojo do artigo analisa a maneira como o autor citado, ainda pouco conhecido, elaborou sua vertente nazista. O argumento mostra que, contrariamente ao suposto por muitos teóricos, o principal, na propaganda totalitária, não é a persuasão, mas o emprego da coação e o trabalho de organização por parte do aparato partidário. A conclusão sumária à análise, defende a ideia que, subjacente a essa unidade, há uma metafísica da vontade de poder, de acordo com a qual o aspecto catártico da propaganda provém do fato de ela ser expressão do poder das massas, de sua predisposição em exercer o poder popular através da coerção organizacional do indivíduo, promovida pelo movimento.

Palavras-chave: propaganda nazista; história da comunicação política; Eugen Hadamovsky.

Abstract: Eugen Hadamovsky and the theory of totalitarian propaganda in Nazi Germany - Nazi propaganda was a milestone in the history of political communication. However, there is no consensus among its theoreticians about its conceptual framework. This premise is proposed to analyze the ideas of one of these theoreticians. The first section of this paper historically contextualizes the so-called totalitarian propaganda, while the main section examines the Nazi mindset, as presented in a tract authored by Eugen Hadamovsky. Based on this, we argue that, contrary to what many theorists suppose, the core of totalitarian propaganda is not persuasion, but the use of coercion and organizational work by the party apparatus. The conclusion summarizes this analysis, defending the idea that, underlying this unit, there is also a metaphysics of will to power, according to which the cathartic aspect of propaganda derives from the fact that it is an expression of the power of the masses, of their predisposition to exercise popular power through the organizational coercion of the individual promoted by the movement.

Keywords: nazi propaganda; political communication history; Eugen Hadamovsky. 
Dentre as principais lições da Primeira Guerra Mundial tiradas pelos partidos radicais, que começaram a surgir ainda em seu final, estão as relativas à prática da propaganda. As agremiações do período anterior, liberais e socialistas, entendiam-na como meio de conquista das consciências e atividade de doutrinação intelectual para uma causa ou movimento. De acordo com Andreucci (1982), os socialistas inovaram ao investir no trabalho de formação ideológica de seus quadros partidários. Porém, eles não chegaram ao ponto de instituir a figura do militante, que só surgiria com os movimentos totalitários. Os agrupamentos mencionados, no geral, compartilhavam a crença de que a opinião e a ação só podiam ser legitimamente mobilizadas pelo uso da razão e respeitando a liberdade individual.

Já os partidos extremistas, que apareceram ao final da Guerra de 1914, foram impactados pelo desenvolvimento de novas técnicas de propaganda durante o conflito. Eles redefiniram seu entendimento, antes cívico, em princípios cada vez mais militares. Contudo, não ficaram nisso. Eles recorreram aos exemplos oriundos da incipiente cultura de massas que estava nascendo nos países democráticos. Em um caso e em outro, tentavam conferir àquelas técnicas um poder de cunho político-partidário massivo. Com eles, a propaganda passou a ser entendida em termos psicológicos e organizacionais, como prática de arregimentação de massas de acordo com objetivos estratégicos.

A figura do agitador, oriunda do período anterior, mas muito ligada à ação dos grupos anarquistas, tornou-se central, sobretudo antes da tomada do poder político. A formação ideológica de quadros dirigentes foi acrescida da tarefa de treinamento de militantes, enquanto se abria mão do trabalho de convencimento doutrinário de um público supostamente racional em favor da mobilização irracional de massas indiferenciadas, pela via do emprego de slogans, símbolos, eventos e uniformes, mas, também, da ameaça, da intimidação e da violência.

Focando o exame dos materiais nas reflexões - sobre a natureza e sentido da propaganda nazista - elaboradas por Eugen Hadamovsky (1904-1945), o texto a seguir tem três objetivos. O primeiro visa explicitar a falta de unidade doutrinária dessa propaganda, a partir de sua contextualização como fenômeno histórico. O segundo consiste em mostra que, de acordo com uma de suas vertentes, o principal, nessa propaganda, não está na comunicação persuasiva, mas no apoio psicológico, moral e estético por ela dado ao trabalho de organização das massas. O terceiro é o de revelar que esse apoiamento tinha origem em uma metafísica da vontade de poder, de acordo com a qual o sentido catártico da propaganda provém do fato de ela, em vez de imposta pelos ditadores, ser antes expressão da força das massas, de sua predisposição em exercer o poder popular através da organização.

Destarte, preconiza-se, no texto, que as ideias do autor são, talvez, o primeiro estágio reflexivo da consciência teórica, apenas posteriormente desenvolvida, de que, em nosso tempo, ruma-se praticamente para o fim da doutrinação ideológica como princípio de coesão social, mas, de outro lado, passando a ter motivação individual ou coletiva no próprio exercício do poder, o sujeito não sucumbe na completa mecanização da conduta, conforme pensaram os últimos teóricos da propaganda (cf. ELLUL, 1965). 


\section{Propaganda e totalitarismo}

Spengler entreviu, ao final da Primeira Guerra, as condições para a ascensão da propaganda totalitária, recorrendo a tinta forte e discurso apocalíptico. Devido ao avanço da técnica e da democracia, o mundo dos livros, com sua variedade, foi eclipsado pelo mundo muito mais padronizado da informação. As pessoas não estão mais, exceto em círculos estreitos, em condições de selecionar e criticar o que leem. "Para a massa, a verdade se torna o que diariamente lê e ouve pelos jornais", converte-se em "produto da imprensa", mas esta, em última instância, está sujeita ao poder político.

Embora o poderio do dinheiro siga sendo a "vontade superior que informa a imagem de seu mundo" (SPENGLER, [1918/1922]1998, p. 568), aos césares da imprensa mundial se imporia a necessidade de transacionar com a caudilhagem dos partidos políticos. O poder passa a ser disputado por movimentos extremistas e forças organizadas militarmente, que procuram "ditar à massa sua vontade, com todos os meios de coação espiritual: lutam pelo poder entre si com métodos à ela ignorados e incompreensíveis e se atacam mutuamente, esgrimindo a arma da opinião pública" (ibid., p. 560).

$\mathrm{Na}$ época em que isso foi escrito, as forças que melhor encarnavam essa visão eram, primeiro, a do movimento comunista e, em seguida, a do movimento fascista. Entre eles, a propaganda se distinguia menos pelas técnicas do que pelo sentido, ainda que seus porta-vozes tenham sido muito econômicos na reflexão sobre o assunto. Ambos estavam de acordo com a ideia de que quem quer que controle os instrumentos de comunicação, a plutocracia ou os partidos extremistas, possuiam o poder de imprimir na consciência das massas as ideias dominantes na sociedade. Para ambos os movimentos, a propaganda era parte do trabalho de organização, que começava dentro do partido, avançava com a mobilização de apoiadores e deveria ter acabamento com a conquista e emprego da máquina estatal.

Os movimentos extremistas partiam da premissa de que todos os meios de doutrinação eram válidos e passíveis de emprego, nenhum era, por princípio, descartável, invejando-se a maneira como as técnicas de propaganda eram empregadas nos países democráticos. O controle do aparelho de Estado era chave para controlar os meios de comunicação e, com sua ajuda, construir seu próprio aparato de coerção e domínio, porque isso é uma função vital e necessária ao funcionamento de qualquer Estado moderno, se ele quiser evitar as tendências anárquicas da vida social.

Na União Soviética, o extraordinário interesse despertado pela propaganda estava ligado ao êxito que consistira a tomada do poder e à conquista de influência sobre vastas camadas da população por um partido de vanguarda, formado por um grupo de intelectuais revolucionários. Na Alemanha, provinha, em vez disso, do debate sobre as causas que levaram o país à derrota militar na Primeira Guerra Mundial. Ludwig Roselius, empresário e marqueteiro de sucesso, sintetizou a tese que acabou se impondo naquela época, ao afirmar que "a Alemanha perdeu a Guerra porque não tirou partido da propaganda do mesmo modo como a América havia tirado" (ROSELIUS, apud WIESEN, 2007, p.109). 
Conforme os movimentos totalitários se foram afirmando, acabou se impondo, à esquerda e à direita, o entendimento de que o poder da propaganda não só era total, mas, em vez de criticado, como o faziam os liberais e social-democratas, deveria ser empregado politicamente. Acreditava-se que ele estava baseado nas leis da psicologia de massas, que se havia posto em marcha com os escritos de Gustave Le Bon. Entre os políticos e intelectuais extremistas, predominava um maquiavelismo tecnocrático, conforme o qual "o povo era conceituado como conjunto de marionetes, facilmente controlado e manipulado pela propaganda" (VERHET, 1997, p. 114).

Lênin e Hitler, por exemplo, estavam de acordo que as massas oprimidas pela ordem liberal burguesa são, nos regimes democráticos, exploradas, enganadas ou corrompidas de modo sistemático, contínuo e cotidiano pela imprensa. "Em todos os países do mundo, liberdade de imprensa significa liberdade para comprar jornais e escritores, subornar, comprar e falsear a opinião pública em benefício da burguesia" (LÊNIN, [1921] 1965, p. 504-509). O entendimento democrático de que as elites devem se orientar pela opinião, em vez de conduzi-las, só serve para melhor dirigi-las, ajuda a esconder o fato de que, espontaneamente, as massas são estúpidas e, portanto, são e devem ser dirigidas (HITLER, [1924] 1939, p. 185).

Eugen Hadamovisky, veremos, fornece prova de que se pode seguir com proveito essa linha de raciocínio, mas ao mesmo tempo nos dá sinais de que se pode ir além dela, se o objetivo é desenvolver o entendimento da propaganda durante a era fascista. Como nota Bussemer (2005, p, 174-195), o seu sentido não era objeto de consenso entre as lideranças do movimento. Havia diferenças entre os que, por exemplo, advogavam a legitimação do regime "pelo emprego dos mais modernos métodos de obter influência massiva" (TAYLOR, 1983, p. 35), a condução do governo por meio da mobilização propagandística, e os que, embora concordassem "que não era intenção mandar com baionetas" (ibid., p. 37), defendiam que o emprego da coação física fazia parte do trabalho de propaganda.

Goebbels pertencia ao primeiro grupo, ele preferia a propaganda à organização, acreditava que, uma vez instalada a ditadura, poder-se-ia governar legitimamente, com muito pouca coerção. Através da propaganda, pode-se convencer as massas das medidas que é necessário pôr em prática, ou pelo menos impedir-las de fazer oposição. A propaganda pode mobilizar as massas, explorando com habilidade, isto é, com a devida linguagem, as suas crenças mais profundas, em vez de meramente martelá-las na sua cabeça, como era o caso antes da revolução nacional-socialista. O fenômeno, em resumo, não seria, nessas condições, senão o ensino prático e cotidiano que se dispensa ao povo, o veículo de uma uma nova forma de pensar coletivamente, que deve, em última análise, estar ajustada à vontade da nação (GOEBBELS, 1931 [1934]).

Hadamovsky só em parte endossou essas teses, ao, nietzscheanamente, ver na propaganda, antes disso, a síntese de uma ideia com a vontade de poder de um coletivo em ação. Para ele, "a propaganda é [essencialmente] vontade de poder", embora "subsidiária de uma ideia", porque "propaganda, ideia e [vontade de] poder estão inseparavelmente conectados" (HADAMOVSKY, 1933, cap. 1). 
O movimento nazista não visava apenas instalar um poder nacional no comando do país: também pretendeia "destruir as estruturas da opinião pública liberal" e, assim, "nacionalizar as massas de forma abrangente" (cap. 4). As referidas estruturas não somente semeavam divisões entre as massas, fragilizando-as, como ofereciam flancos abertos para o ataque da propaganda de seus inimigos. O princípio da liberdade de opinião precisa, pois, ser suprimido, se é para se manter a unidade nacional e permitir que venham à tona a força e instintos do povo alemão.

A verdadeira opinião pública não surge do confronto de ideias, mas do trabalho de organização, visto que a propaganda precisa ser entendida como "a expressão unificada e sob comando da vontade [nacional em ação]" (ibid., cap. 2). As massas possuem impulsos próprios que, nos regimes liberais e democráticos, são objeto de disputa pelas forças políticas organizadas, tornando-se incapazes de se conduzirem por conta própria. O poder que lhes é intrínseco se dispersa, sempre que seus impulsos não são devidamente canalizados por um esforço de organização totalitário, dentro do qual se insere e sem o qual não há como devidamente se entender a ação de propaganda.

\section{Propaganda e vontade de poder}

Eugen Hadamovsky pertenceu à geração que encontrou nos partidos extremistas a forma de responder à crise econômica e moral do pós-Guerra. Tendo estudado mecânica por conta própria, peregrinou, durante os anos 20, por vários países da Europa e norte da África. De volta a seu país natal, especializou-se em tecnologia de radiodifusão e ingressou no partido nazista em 1930. Designado diretor do Serviço Nacional de Radiodifusão do Reich, após a indicação de Hitler para chefiar o governo, tomou as medidas necessárias para controlar o acesso aos postos de trabalho e o exercício profissional nesse setor como vice-presidente e, posterioremente, presidente da Câmara de Radiodifusão do Ministério da Propaganda.

Em 1935, decretou o banimento do jazz do rádio alemão e assumiu a direção do primeiro serviço de transmissão de sinais regulares de televisão na história, com o objetivo central, segundo suas próprias palavras, de "plantar a imagem do Führer em todos os corações alemães" (apud URICCHIO, 1999, p. 1).

Apontado por seus próprios camaradas como um homem possuído "pelo entusiasmo incontrolável dos que nascem fanáticos" (BOELCK apud WELCH, 2002, p. 40), Hadamovsky acabou entrando em conflito com Goebbels durante a Guerra, sendo rebaixado a chefe do Escritório Central de Propaganda do Partido em 1942. Pedindo transferência para as tropas da SS ${ }^{1}$, em 1944, morreu em combate, nas proximidades de Rummelsburg (Polônia) em 1945.

Autor de obra variada, observa que a propaganda dos modernos movimentos de massa, o fascista como o bolchevista, diferencia-se de outras porque não tem apenas um sentido doutrinário, possuindo um sentido principalmente estratégico e organizacional,

1 Abrevitura de "Schutstaffel", tropa de elite criada pelo partido nazista em 1925. 
como, aliás, já tinha sido sublinhado por Lênin e Hitler (HITLER [1924] 1939, p. 579-585). Desses, Hannah Arendt não por acaso sacou a conclusão, seladora de sua própria teoria, segundo a qual "o verdadeiro objetivo da propaganda totalitária não é a persuasão, mas a organização" (ARENDT [1951] 1974, p. 447).

O propagandista em foco, contudo, explorou mais a fundo esse entendimento, conferindo-lhe feições realmente originais, ao pregar que o seu principal esforço se deve ao sentido de mobilizar e explorar o controle das forças massivas de acordo com um programa em que essas forças, em vez de serem anuladas, devem ser ordeiramente levadas ao seu máximo.

A propaganda que ajuda a manter no poder "os sistemas [totalitários] que conquistaram o controle do governo" não é meramente ideológica, é também e, sobretudo, "prática [organizada] da vontade de poder [das massas]" (HADAMOVSKY, 1933, cap. 2). A sociedade contemporânea projetou as massas na vida política e, assim, a ação política não tem mais como levar em conta o ponto de vista do indivíduo. A explosividade, flexibilidade e instantaneidade, como grupo, estão passando a predominar e, onde isso ocorre, o "indivíduo deixa de ser importante". A propaganda de vanguarda é uma função de seu movimento; seu sentido, do ponto de vista totalitário, é tornar a massa amorfa e apática "numa massa pronta para o combate".
A propaganda pode ser definida, nesse sentido, como a arte de exercer o poder sem possuir os seus meios, é o segredo através do qual os oprimidos podem sobrepujar os poderes existentes, quando se asseguram de sua própria força [isto é, quando se organizam] (lbid., cap. 2).

Orientados por ela, a literatura, o cinema, o rádio, a televisão, o teatro e outros aparatos, por exemplo, não deveriam evitar a diversão, mas "combinar o entretenimento e o prazer com a educação orientada de acordo com o movimento [nacional socialista]". O principal é que eles superem as tendências individualistas, tomem como referência "a necessidade de massa mais profunda", em vez do seu gosto superficial e imediato, explorado pelos capitalistas (ibid., cap. 7).

As pretensões do velho liberalismo em doutrinar a massa apenas servem à manutenção do poder por parte da burguesia, porque a chamada opinião pública, a quem invoca, não passa de meio para manter o capitalismo. A opinião pública não pertence às massas, é antes a elaboração de seus humores e a anestesia de seus impulsos revolucionários por parte dos seus intelectuais, via os meios de comunicação.

No lugar da opinião pública formada pelos interesses privados, o futuro inevitavelmente produzirá uma vontade tempestuosa, unificada e gigantesca de interesse político nacionalista, não apenas para situações de crise, mas por um longo período histórico (Ibid., cap. 2).

Goebbels sustentava que "o propagandista deve ser capaz de entrar no mundo das massas mais amplas e sair dele conhecendo seus desejos e esperanças" (1934, p. 1), 
para pô-las a serviço do partido, mediante sua articulação doutrinária. Hadamovsky avançou em relação a esse entendimento. Segundo ele, a propaganda totalitária não se limita a engajar ideologicamente as massas, almejando ainda liberar sua vontade de acordo com um projeto de expansão do poder nacional. Os liberais desprezam os humores invisíveis que existem entre as massas, restringindo sua propaganda aos fatores que podem controlar em benefício próprio. Os conservadores temem, procurando estabelecer censuras e proibições em cima de suas condutas. O fato, porém, é que as massas não têm como serem pura e simplesmente controladas, nem se limitam a agir de acordo com a racionalidade econômica: elas são a base ou fonte de poder da liderança (cf. ARENDT, [1951] 1974, p. 399).

Hadamovsky aparentemente estava sintonizado com as tendências intelectuais que, na República de Weimar, elaboraram uma interpretação nietzschiana do progresso tecnológico e da ascensão das massas (cf. JÜNGER, [1932] 1990; LOSURDO, 1991; HERFF, 1993). Os movimentos totalitários, Hadamovsky crê, retiram sua força da criação de métodos e emprego de meios técnicos modernos para liberar e explorar os impulsos e fantasias das massas e em favor de um regime cujo sentido é massivo. Por isso, convém matizar a tese sobre o caráter de mediação espetacular e catártica do medo e terror que, para as massas, teria a propaganda fascista, segundo autores como Adorno e Kracauer.

Para Adorno, o fenômeno teria uma função essencialmente gratificante, estética e psicológica, em vez de ideológica (no sentido de formar a consciência com ideias, de articular uma crença). O próprio da propaganda fascista seria o caráter de espetáculo, visto que o fascismo não necessita de doutrinação ideológica, ao bastar-se com o emprego da coerção física e do arregimento forçado. O fenômeno se caracterizaria pela promoção de experiências vicárias, em que as massas se divertem, em meio a um regime cuja política, em síntese, baseava-se no terror e, assim, possuía no medo a base de sua aceitação entre as massas (cf. ADORNO [1951] 2004, p. 400-405).

Segundo Kracauer, a propaganda fascista seria um meio de mascarar a política de terror em que se sustenta o regime, de manter a atomização social em que este se baseia, lançando mão da aparência de integração social dos indivíduos. O seu sentido seria criar encenação relativamente virtual de uma reintegração da massa atomizada pelo movimento do capital no âmbito ideológico da nação. As concentrações, paradas, eventos e comunicações por ela concebidas visariam criar o mito de que isso tudo representa objetivamente o povo, enquanto, na verdade, esconde sua submissão terrorista à ditadura, através do manto ideológico do culto à personalidade do Führer (KRACAUER, [1936] 2012).

Entrementes, Goldhagen (1997), Götz (2006) e outros (Cf. SWETT; ROSS; D'ALMEIDA, 2011) vêm provocando polêmica, ao mostrar que, se não foram todos cúmplices dos piores crimes, como defende o primeiro, os alemães pelo menos se beneficiaram materialmente das políticas extremistas patrocinadas pelo regime, acabando, em sua ampla maioria, por aceitá-las livremente, enquanto aquelas Ihes traziam vantagens. 
Por isso, não basta dizer que, embora inovasse com seu caráter fortemente performático, o verdadeiro fundamento da propaganda era o terror, como o faz Kracauer. Nem parar no reconhecimento feito por Adorno de que as condutas promovidas pela propaganda fascista não são resultado de contágio meramente passivo, de que seu consumo e rituais contam com a participação consciente e voluntária do sujeito individual em condições determinadas.

Deve-se avançar até o ponto de se reconhecer também que, embora não o interpele como criatura racional e autônoma, o regime, pelo menos até 1941, baseou-se, sobretudo, no terror e apenas excepcionalmente "tratou [os alemães] como meros objetos de medidas administrativas, ensinando-os a serem modestos e a obedecer ordens" (ADORNO, [1946] 2004, p. 372). Hadamovsky o confirmaria, ao defender que a repressão e o controle jamais atingem suas metas se as massas lançam mão de seu poder - algo que, ainda segundo o autor, só foi compreendido pelos movimentos totalitários. O controle e repressão devem se apoiar na força das massas, para chegarem ao máximo.

Para ele, as propagandas fascista e comunista têm uma unidade. Ambas visam dar uma base de massas a um projeto político, empregando tecnicamente esse meio, mas conscientes de que "o poder construído apenas com base na propaganda flutua e pode se desintegrar de um dia para o outro, a menos que o poder da organização seja acrescentado ao da propaganda" e, por isso, sublinhou, a propaganda pode ser combinada com a coação, "o uso da coação [pelas, entre e sobre as massas] pode ser uma parte da propaganda" (HADAMOVSKY, 1933, cap. 2).

\section{Massa e potência}

Hadamovsky observa de maneira sinistra, considerando os crimes de guerra que viriam mais tarde, que a propaganda é sempre preparação para a ação política e, eventualmente, marcial "para as coisas que terão de ser feitas amanhã" (HADAMOVSKY, 1933, cap. 3; cf. HITLER, [1924] 1939, p. 586). As concentrações perante os palanques têm, nesse sentido, um papel fundamental: elas permitem às lideranças fazer contato direto com a vontade de onde nascem as ações, promovendo o exercício do consentimento mais imediato, espontâneo e catártico de forma massiva. Os indivíduos podem se influenciar através dos meios de propaganda, mas só a mente de massas criada em presença unifica as ações de muitas pessoas: nenhum jornal, microfone ou filme tem como fazer frente a esse tipo de fato vivo.

Embora tenham seu papel, meios como esses, em última análise, assumem a causa da propaganda de forma enganosa. A influência sobre as massas, que por meio deles se exerce, tende a prendê-las, a conter seu movimento, em vez de, como na concentração, satisfazer "o desejo das massas em ter uma experiência realmente coletiva e pessoal". "A reunião em massa é a mais poderosa forma de propaganda que possuímos" (HADAMOVSKY, 1933, cap. 4), embora as paradas também provoquem o sentimento 
de poderio coletivo e revelem "a admiração incondicional que as massas conferem à força, através da exibição de seus símbolos" (HADAMOVSKY, 1933, cap. 4): ambas proporcionam catarse, mas, ao mesmo tempo, criam expectativas favoráveis em relação aos serviços e sacrifícios que a pátria exige.

A propaganda liberal tinha como horizonte o convencimento mediante a palavra; a fascista usa a palavra para promover a força, porque propaganda da força é a forma mais forte de adquirir influência, de se conquistar as massas e, em seguida, demonstrar toda a força e poder que se dispõe por meio delas, que elas podem exercer sobre a vida e os inimigos. A política é a vida e, por isso, os meios devem ser políticos vitalmente, mais que ideologicamente. Os regimes totalitários, genericamente, reivindicam com razão uma superioridade sobre os liberais, porque não apelam à consciência, baseiam sua propaganda no engajamento concreto das massas em ações organizadas.

Por isso, a propaganda não pode ser pontual, mas sim permanente: se é totalitária, nota o Hadamovsky, é porque, para além das razões técnicas, encarna uma "função [permanente] da vida [nacional]" (Ibid, cap. 4). "O rádio, a imprensa, o filme e o teatro, tanto quanto os eventos de massa e as celebrações nacionais e militares, devem ser um elemento permanente no sistema educacional" (ibid., cap. 7). O propagandista, mais que ensinar ou persuadir, encarna uma visão de mundo: seu trabalho consiste em vestir as massas com essa visão, mas "ao poderio iluminador e dirigente do intelecto, não pode faltar o espírito das massas, como seu eco e sua fonte" (ibid., cap. 4).

A variedade e pluralismo de ideias, que ensejam a dúvida e a confusão, devem ser eliminados dos meios de comunicação, precisamente por causa disso: a liberdade individual enfraquece a expressão da vontade coletiva, nacional. As comunicações devem servir aos objetivos do partido, formar a vontade nacional, ajudar na "construção consciente do tipo político que personificará e salvaguardará a força e unidade da nação" (Ibid, cap. 4), mas, salienta o autor, por outro lado, isso não será trabalho só dos meios ou dos intelectuais, também o será das organizações de ouvintes, dos círculos de leitura, clubes de cinema e demais organizações de massas lideradas pelo partido onde podem ter papel os meios de comunicação.

Dessa forma, a função dessas organizações é estabelecer contato entre as massas e suas lideranças, através da ação direta de seus integrantes; eliminar o egoísmo individual e a estupidez coletiva, tornando os veículos de comunicação meios de criação de um novo homem, ajustado às necessidades do poderio nacional. $\mathrm{O}$ controle dos meios, como o rádio, por exemplo, "não previne de modo algum a presença de forte movimento de oposição entre os ouvintes, tanto quanto entre o pessoal artístico" (Ibid, cap. 4). A tarefa das organizações começa aqui, no enquadramento dos profissionais e do público em novas estruturas sociais, submetidas ao controle e escrutínio pelas lideranças do movimento. O seu fundamento, por isso, não reside nem no individualismo, nem no comunismo, mas no movimento criador de uma forma superior de comunidade, cujo sentido é a construção de um novo tipo humano, em que as massas acabarão sendo sublimadas, após o término de sua tarefa e a vitória final (ibid., cap. 4). 
Portanto, não deve haver dúvida de que a primeira e mais importante tarefa deveria ser a construção, com todos os meios de opinião pública, de um tipo [humano] nos estabelecimento de ensino e universidades. A vida dos alunos deve ser, desde o princípio, organicamente ligada à comunidade. (lbid., cap. 7)

Segundo Hadamovsky, o poder da imprensa jamais se originou dela mesma, mas do liberalismo econômico, industrial e financeiro, que controlava a formação da opinião pública desde que esta apareceu. "O individuo não tem como se defender das notícias enquanto está sozinho. Quando as notícias não são controladas e questionadas, atingindo milhões em vez de milhares de indivíduos [isolados], pode ocorrer pânico em massa em escala sem precedentes" (HADAMOVSKY, 1933, cap. 4). Quando as massas começam a se organizar, todavia, isso começa a mudar, as pessoas começam, como coletivo, a se sentirem fortes e esse poder vem abaixo. O movimento nacional-socialista é a encarnação de uma crença numa ação massiva organizada, uma espécie de propaganda vital objetivada, contra ada imprensa, muito mais fraca, pouco pode. "O poder da imprensa se rompe ao ter de lutar contra o poder de uma organização vital e, por isso, não passa de arma de valor tático limitado na luta contra o avanço de tal organização" (ibid., cap. 4).

Devidamente examinados, verifica-se que os aparatos de propaganda à distância só têm efeito indireto, não têm como "conter ou quebrar um movimento que se projeta poderosamente" (Ibid, cap. 5). Os veículos do partido o ajudaram, sim, a tomar o poder, mas só como parte do movimento. Quem enfrentou e venceu a oposição da maioria da imprensa foi o movimento de massas"(Ibid, cap. 5). A página impressa não tem como excitar ou controlar os impulsos de massas": se houve poder por parte daquela, ele se deveu ao fato de que as pessoas estavam isoladas. O liberalismo burguês explorava mercantilmente as massas com o disfarce do discurso da opinião e, por isso, em vez de promover a liberdade de imprensa, pôde inclusive servir ao que sujeitava a nação, como acabou ocorrendo durante a Primeira Guerra.

\section{Conclusão}

Em seu conhecido estudo sobre cultura e tecnologia no III Reich, Jeffrey Herf (1993, p. 85-125) observa que, entre as tendências sobre o assunto com curso à época, havia uma de acordo com a qual a tecnologia se tornara um valor em si próprio, em que se encarnara uma vontade histórica, materializara-se o espírito ou alma nacional. A cultura estava passando a emergir de dentro do movimento expansionista dos meios técnicos, porque este continha um sentido mais necessário e profundo, responsável pelo engendramento de uma espécie de "realismo mágico", como disse um de seus porta-vozes, Ernst Jünger.

Para este, com efeito, o progresso técnico e o avanço das formas de vida urbana, os automóveis e aviões, o rádio e os cartazes, as fábricas e usinas, os comícios e 
as aglomerações humanas baseavam-se numa vitalidade cada vez mais rígida, sistemática e autoritária. A liberdade individual sucumbe, quando o poder de cada um se torna função da posição que ocupa numa engrenagem que, embora anestesie em relação aos sofrimentos morais que isso acarreta, não importa na perda da capacidade de desfrutar esteticamente a nova realidade.

O principal, porém, era a ideia de que, debaixo da aparente frieza e instrumentalidade da tecnologia, haveria uma figura ou força mais ampla, promotora do nascimento de uma nova forma de vida. O poderio oriundo da tecnologia seria, portanto, "signo de uma nova raça, cujos desejos superam as atuais ideias e já não se satisfazem mais com nenhuma imagem do passado" (JÜNGER, [1930] 1990, p. 140).

Vimos no presente estudo como essa concepção foi levada para o campo da teoria da propaganda pela vertente do fascismo alemão encarnada nas ideias de Hadamovsky. Para ele, o fenômeno não tem força própria, precisando ser visto como função complementar do trabalho de organização. O principal na mobilização de massas, procurado pelo regime, não é de caráter psicológico ou simbólico. O fundamental está na ação objetiva de uma estrutura sociológica, que condiciona a conduta em um dado sentido, mas isso não quer dizer à revelia dos fatores metafísicos.

O caráter prático e organizacional da propaganda de nossa era não é meramente recoberto pelos apelos emocionais que vão tomando o lugar dos princípios ideológicos. A exploração desse apelo é essencial na mobilização das massas em relação às ações mais radicais que, de acordo com suas propostas, cumpre executar, para fazer avançar o poder nacional.

Inspirando-se na psicologia de massas de Le Bon, conforme ela foi apropriada pela teoria da propaganda de Plenge (1922), Hadamovsky defendeu o autor afirmando que a função da propaganda não é politicamente negativa. O caráter coativo do trabalho de organização em que ela se baseia possui um sentido libertador, se inserida no que, contraditoriamente, tem sido chamado de biopolítica (cf. CUTRO, 2005; ESPOSITO, 2006). Para ele Hadamovsky (1933, cap. 2), seu propósito último não é manter a massa dominada, mas antes em estado de mobilização, preparada para cumprir tarefas, "pronta para o combate [contra os inimigos do poder nacional]".

Hadamovsky logrou transcender o entendimento psicológico e, portanto, ainda idealista da propaganda totalitária (REICH [1934] 1974), observando a dependência de sua propriedade e eficácia ao emprego da coerção física e ao trabalho de organização (que outros, mais tarde, vinculariam ao que chamaram de fenômeno técnico ou sociedade tecnológica [ELLUL, 1965]).

Porém, parece-nos que foi além, sublinhando positivamente a conexão dos seus fundamentos organizacionais com a metafísica da vontade de poder que, promovida pelos setores dominantes no movimento nazista, articulara-se filosoficamente na obra de Nietzsche (cf. BOYER et al., 1994; APPEL, 1999; ARIAS, 2002). A propaganda, sim, tem um aspecto estético e catártico, mas este provém do fato de ela, antes, ser expressão do poder das massas, de sua predisposição em exercer o poder popular através da organização 
partidária e estatal. O povo alemão o mostrou militarmente no banho de sangue em que jogou a humanidade durante a Guerra Mundial de 1939-1945.

Francisco Rüdiger é doutor em Ciências Sociais pela Universidade de São Paulo e docente das Faculdades de Comunicação da Pontifícia Universidade Católica e da Universidade Federal do Rio Grande do Sul. Publicou recentemente A mídia e o amor (Editora da UFRGS, 2013)

frudiger@ig.com.br

\section{Referências}

ADORNO, T. La teoria freudiana y el modelo de la propaganda fascista. In: Escritos sociológicos I. Madri: Akal, [1951] 2004.

. Antisemitismo y propaganda fascista. In: Escritos sociológicos I. Madri: Akal, [1946] 2004.

ANDREUCCI, F. A difusão e a vulgarização do marxismo. In: HOBSBAWN, E. (org.): História do marxismo II. São Paulo: Paz \& Terra 1982.

APPEL, F. Nietzsche contra democracy. Ithaca: Cornell University Press, 1999.

ARENDT, H. Los orígenes del totalitarismo. Madri: Taurus, [1951]1974.

ARIAS, J. Nietzsche y las nuevas utopias. Madri: Valdemar, 2002.

BOYER, A. et al. Por que não somos nietzscheanos. São Paulo: Ensaio, 1994.

BUSSEMER, T. Propaganda. Wiesbaden: VS Verlag, 2005.

CUTRO, A. (org.) Biopolitica. Nápoles: Ombre Corta, 2005

ELLUL, J. Propaganda. Nova York: Knopf, 1965.

. A técnica e o desafio do século. Rio de Janeiro: Civilização Brasileira, 1968.

ESPOSITO, R. Bíos: biopolítica y filosofia. Buenos Aires: Amorrortu, 2006.

GOEBBELS, J. Der Kongress zur Nürenberg. Munique: Zentralverlag, [1931]1934. (Tradução para o ingles de Phil Taylor: Goebbels on propaganda - Phil Taylor's web site - internet, 2003).

Erkenntnis und propaganda. In: Signalen der neuen zeit. Munique: Zentralverlag, 1934. (Tradução para o inglês de Randall Bytwerk - German propaganda archive - internet, 2000).

GOLDENHAG, D. Os carrascos voluntários de Hitler. São Paulo: Cia. das Letras, 1997.

GÖTZ, A. Hitler's beneficiaries. Nova York: Holt, 2006.

HADAMOVSKY, E. Propaganda und nationale macht. Oldenburg: Gerahrd Stalling, 1933. (Tradução para o inglês de Randall Bytwerk. German propaganda archive. Disponível em <www.calvin.edu/ academic/cas/gpa>. Acessado em 23 Nov. 2012. O texto está dividido em capítulo, sem numeração de páginas. Há edição da Arno Press - Nova York, 1954).

HERF, J. O modernismo reacionário. São Paulo: Ensaio, 1993. 
HITLER, A. Mein Kampf. Londres: Hurst \& Blackett, [1924]1939.

JÜNGER, E. El trabajador. Barcelona: Tusquets, [1932]1993.

La mobilization totale. Paris: Gallimard, [1930]1990.

KRACAUER, S. Masse und propaganda. In: Studien zu massmedien und propaganada. Berlin: Surhkamp, [1936] 2012.

LÊNIN, V. I. A Letter to Myasnikov. Collected Works, v. 32. Moscou: Progresso, [1921]1965.

The character of our newspapers. Collected Works, v. 28, Moscou: Progresso, [1918]1974.

LOSURDO, D. Heidegger e I'ideologie della Guerra. Turim: Bollati Boringhieri, 1991.

PLENGE, J. Die Lehre von der Propaganda als praktische geselleschaftlehre. Bremen: Angelsachsen, 1922.

REICH, W. A psicologia de massas do fascismo. Porto: Escorpião, [1934]1974.

SPENGLER, O. La decadencia de Occidente. Madri: Espasa, [1918/1922]1998.

SWETT, P.; ROSS, C.; D'ALMEIDA, F. (orgs.). Pleasure and power in nazi Germany. Londres: Palgrave, 2011.

TAYLOR, R. Goebbels and the function of propaganda. In: WELCH, D. (org.). Nazi propaganda. Beckenham: Crom Helm, 1983.

URICCHIO, W. Envisioning the audience. E-view, Amsterdam, n. 1, p. 1-15, 1999.

VERHET, S. Some lessons of the war: the discourse on propaganda and public opinion in Germany in the 1920s. In: HÜPPART, B. (org.). War, violence and modern condition. Nova York: De Gruyter, 1997.

WELCH, D. The Third Reich - politics and propaganda. 2a. ed. Londres: Routledge, 2002.

WIESEN, J. Creating the nazi marketplace. In: SWETT, P; WIESEN, J.; ZETLIN, J (orgs.). Selling modernity. Durham: Duke University Press, 2007. 